\title{
CONHECIMENTOS DA MINHA CULTURA
}

Txiarawa Karajá

Orientador de Estudo

\section{RESUMO}

A minha pesquisa foi feita na Comunidade Indígena Iny (Karajá) de Santa Isabel do Morro, situada na Ilha do Bananal - TO. A aldeia fica à beira do Rio Araguaia (Berohokỹ), do lado do estado do Tocantins, próxima da cidade de São Félix do Araguaia-MT. A pesquisa foi realizada com seis famílias diferentes: (1) família da Kuaxiru Karajá; (2) família de Tewahura Karajá; (3) família de Dirasi Karajá; (4) família de Kuriwiru Karajá; (5) família de Dorewaru Karajá; e (6) família de Siari Karajá. Esses são os anciãos e as anciãs que participaram do nosso estudo sobre o Ciclo da vida do Iny.

PALAVRAS-CHAVE: Ancião. Família. Ciclo da vida.

\section{TURYBÈNABUTÈ}

Hãwalo mahãdu-ki rewinyre rybe itxisena, Itytibuteki roimyhỹreki. Hãwalo heka Berohokỹ ijàki roimyhỹre, TO. -ki, hãwahakỹ riore rbi ioholemy (São Félix do Araguaia). Debo-ò sohoji iny soemy inymymahãdu-ò lỹỹraxi rewinyre: Kuaxiru sỹmahadu; Tewahura sỹmadu; Dirasi sỹmahadu; Kuriwiru sỹmahadu; Dorewaru sỹmahadu; Siari sỹmahadu. Kamahãdu rỹireri wna rewinyrenyre iny ratbienymyre bdedỹỹnanamy rybe.

RYBÈ WÈRYNA: Iumymahadu. Sỹmahadu. Iny ratbienymyhỹre bdedỹỹnana.

\section{SABERES INY}

Existem as diversidades culturais no país. Cada povo tem sua cultura diferente, sua língua e seu costume. Existe também 
a epistemologia de cada povo diferente, organização, concepção do mundo. Cada grupo tem sua maneira de interpretar o mundo, conforme seu ambiente onde ele vive. Por isso que você percebe a pintura corporal diferente e organização diferente. Você se engana quando você vê pintura e pensa que todas as etnias se pintam iguais, não, isso não é verdade, cada etnia se pinta de acordo com organização social do seu povo.

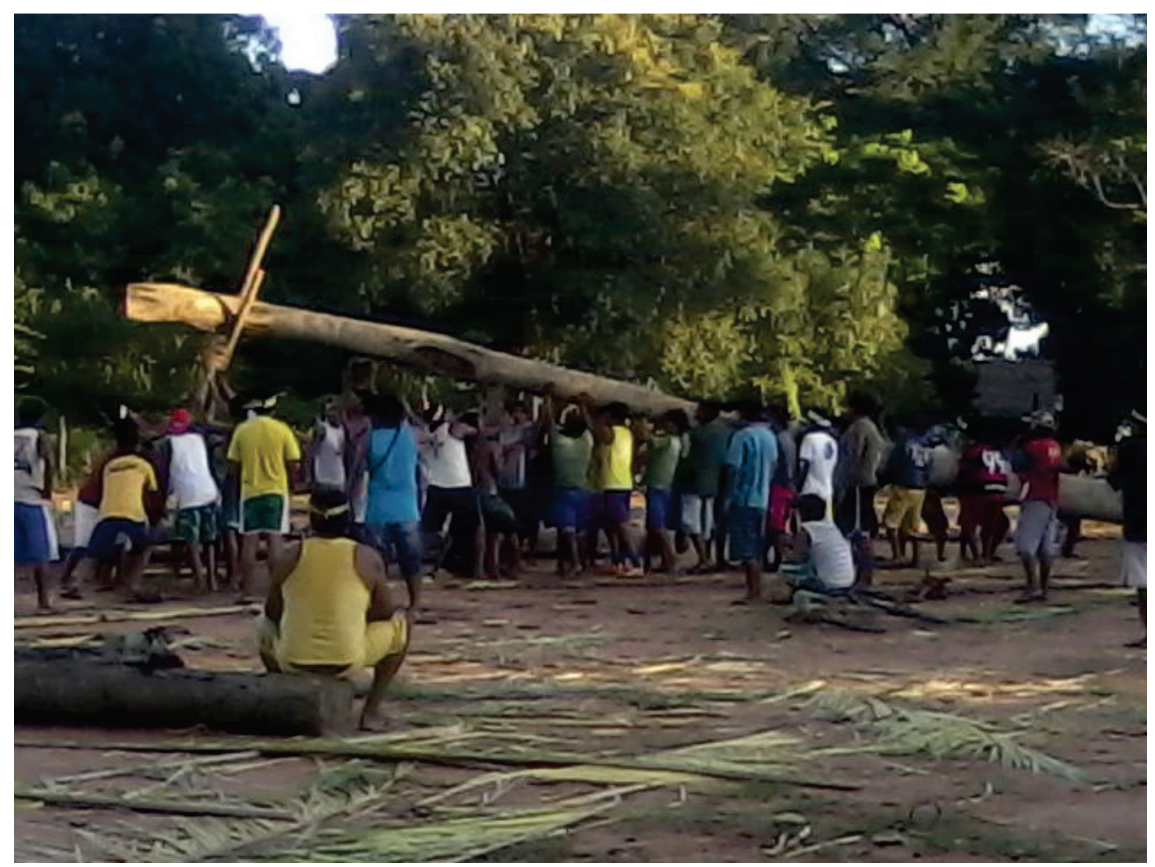

\section{ORGANIZAÇÃO E RESPEITO}

Segundo mais velho relata que, há muito antes da chegada dos povos europeus os índios tinham organização própria. Ou seja, a estrutura da aldeia, arquitetura, na pescaria, na roça, nos rituais, enfim. Ele disse que o nosso povo era muito unido e era forte. Na parte da cultura, e entre o povo Iny tem união, e quaisquer atividades que acontecem seja nesta de aruanã, principalmente a festa de iniciação a fase de meninos para a vida adulta, conhecido como "Hetohoky" (na língua portuguesa é Casa Grande). Esta imagem mostra a união de força do nosso povo. 
Dentro da sociedade Iny a chefia era hierarquizada. Passado de pai para o filho. Tinha plano para realizar e executar seu projeto de vida. Eles se planejavam com antecedência para praticar sua atividade como roça, pescaria, ritos e outros. Era tudo organizado.

$\mathrm{Na}$ sociedade Iny existe certa divisão de grupo, chamado de Iòlò e Deridu. Cada um tem seu papel diferente interno e externo. Iòlò e Deridu tinham poder sobre seu povo, eles são chefes gerais da comunidade. Quando os visitantes chegam em sua aldeia ele recebe seja bem recebido e com todo respeito. Ele tinha todo poder de interromper a guerra. Traz a paz, segurança, alegria, conselho para o povo.

Assim, Deridu e Iòlò tinham suas lideranças para facilitar o trabalho e para liderar o pequeno grupo.Entrevistei o ancião Tewahura Karajá, conhecedor da nossa cultura. Segundo ele “ antigamente o nosso povo era assim, o Iòlò era muito importante, quando ele acompanha pessoais para pescaria ou para qualquer lugar que seja, sempre tem pessoa que carregar na costa. Iòlò em si não vai a pé, porque não pode tocar no chão."

O líder tem responsabilidade enorme dentro da aldeia, ele coordena as atividades como a roça de toco. O líder reúne o grupo antes de iniciar sua atividade, porque roça de toco tem seus períodos certos. Período de derrubar, roçar, plantar e colher.

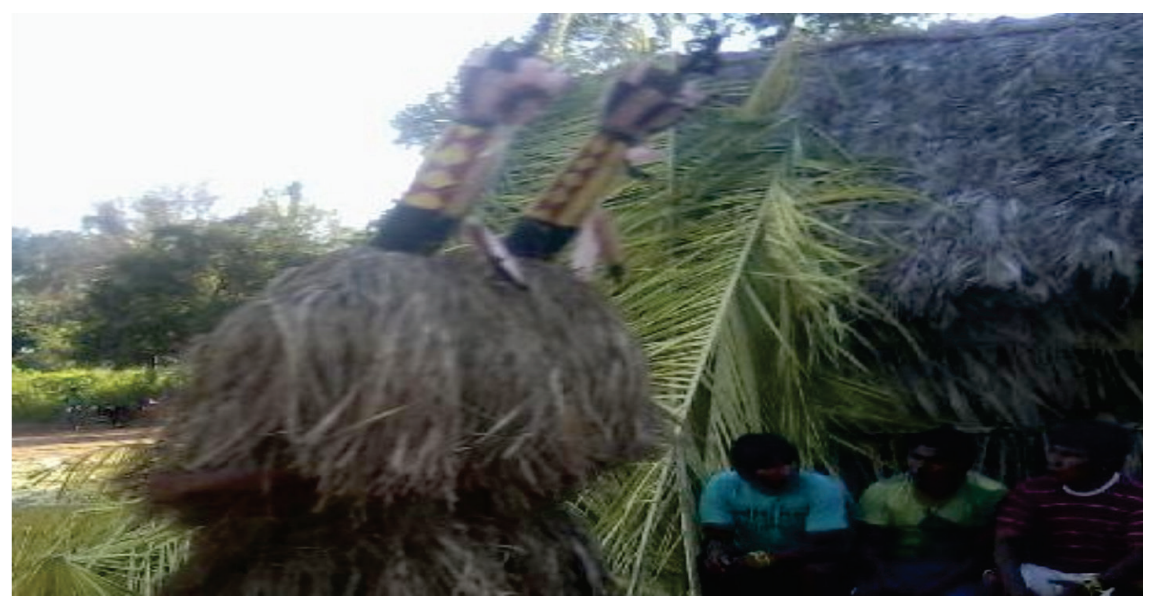

Os homens têm seu local próprio, onde eles reúnem e tomam decisão. Esse local chama-se casa dos homens (hetokre ou ijoina). 
Existe outra chefia chamado Cacique, surgiu durante o contato. $\mathrm{O}$ cacique foi adotado pelo não indígena para ter o contato entre indígena e ao mesmo tempo facilitar acesso.

Antigamente, os índios se pintavam nos rituais, nas cerimônias e nas guerras. A pintura corporal é muito importante para identificar por ser Iny. Usava no dia a dia tanto adultos quanto as crianças. Com o passar do tempo, cada vez, mais, com influência da sociedade envolvente, a tecnologia e tudo, vem enfraquecendo e deixando de pintar-se no dia a dia, isso não faz parte do cotidiano do povo Iny. E, foi a mudança do tempo. Mais ou menos, $30 \%$ por cento os jovens deixaram de se pintar, $70 \%$ ainda se pintam ainda. Isso é preocupante para nossa comunidade, é porque a pintura faz parte da sustentabilidade do nosso povo.

A pintura corporal usada na festa cultural como Festa de Iniciação de menino para a vida adulta, conhecida como Hetohoky, a primeira mestruação da menina, e outro. No dia da festa é o momento de jovens se pintarem para participar da festa, dançar, cantar, lutar e ficar bonito na festa. Enquanto a menina, quando termina menstruação da menina se pinta o corpo inteiro para participar da cerimônia da fase de menina para vida adulta. Hoje em dia também a pintura corporal usada nos eventos seja na aldeia quanto na cidade. Está sendo comercializada e usada como atração turística, na temporada de praia, no encontro. Muitas vezes os turistas encomendam para fazer a pintura no braço, na perna e depende que ele ache bom, tem uns que gostam de pintar o corpo inteiro e tem uns que não. Por isso que a perspectiva da nossa comunidade valorizar mais o conhecimento dos anciãos e anciãs. Existe muito conhecimento jogado fora e sem proveito, nós não percebemos isso.

Outra que nos preocupa mais o conhecimento dos anciãos ficam na memória dele é muito risco de perder, porque muitos foram embora e conhecimento vai junto. E a nova geração como seria? Como eles vão aprender nossa cultura, nossa história, dança, conto, e outro? Temos que respeitar muito, acompanhar bem, ouvir muito o que dizer o nossos anciãos para poder aprender com eles. Existe bastante desrespeito na nossa cultura. Eu me lembro quando minha avó Belawaru Karajá dizia todos os dias antes de dormir, à noite a criança dorme mais cedo, também não pode brincar durante 
noturno, diz que somente alma ou espírito poderia brincar à noite. Mas, ela tem mania de contar história à noite. Então ela arrumava esteira e chamava a gente para deitar na esteira e começava contar história. Enquanto o nosso olhar no céu a gente via a constelação, lua, era muito gostoso de ouvir a história maravilhosa. Ela fazia parte dela, para educar e nos transformar como cidadão iny, para ser bom garoto, ter respeito aos mais velhos, ter responsabilidade na vida, aprender a lição de vida para seguir em frente. Ela semeava a semente para ter bom fruto no futuro. Com a chegada de tecnologia mudou bastante, quase todo mundo tem televisão na casa, DVD, vídeo só querem assistir o filme de terror, novela, e o programa que não tem nada a ver com nossa cultura.

\section{CICLO DE VIDA}

Festa: primeiro toca alimento na criança

Depois de dois meses de nascimento da criança, a família prepara os alimentos a serem usados durante a festa. Os alimentos são: mandioca, peixes, melancia, banana, tartaruga, mel, batata doce, farinha de puba, milho, cana de açúcar etc. Em relação aos alimentos que foram colocados acima depende da família, porque muitas vezes nem toda família tem os alimentos. Essa festa tem que ter muitos alimentos.

'Essa festa nem sempre nascimento da criança Iny, só quando é o primogênito do casal. Tem que ser a pessoa muito importante para tocar alimento na criança, uma pessoa exemplo da comunidade. E depois a criança está liberada para comer os alimentos. 


\section{CASAMENTO}

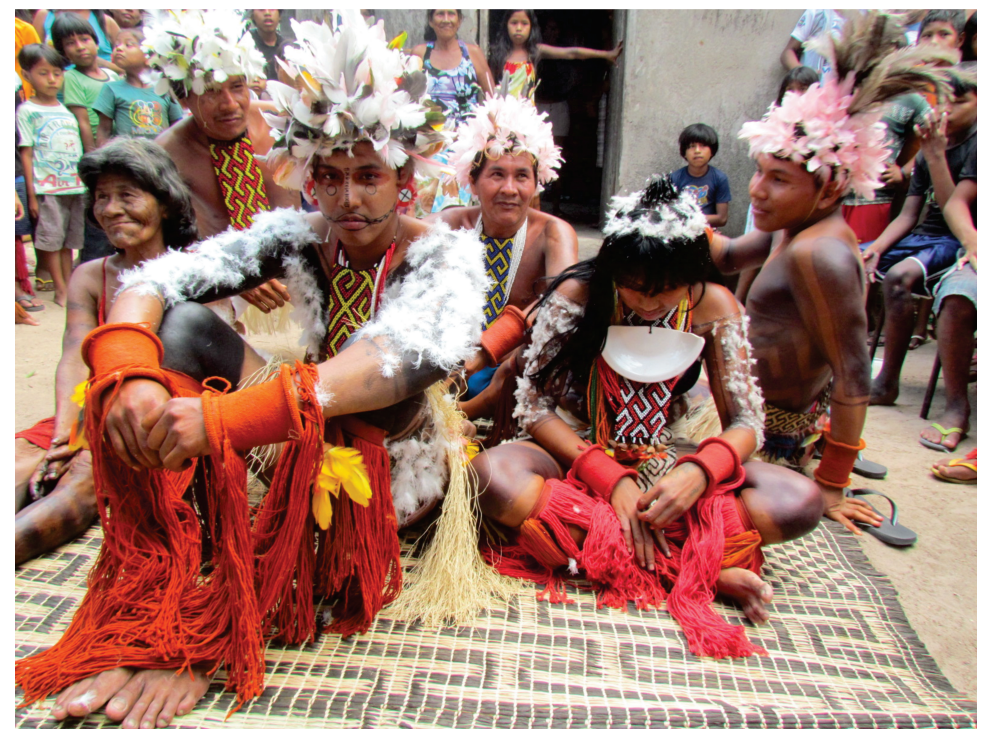

Cada povo tem sua tradição diferente, tinha lei, regra era muito rígido e respeitado. Assim, o iny tinha a lei de casamento. Dentro da sociedade Iny existia a lei que não permitia casar com a pessoa estranha, podia casar com sua linhagem familiar, porque não pode misturar sua linhagem com a outra linhagem. Segundo mais velho o casamento é muito importante para o povo Iny, é a união familiar e geração nova para comunidade, onde se forma um casal feliz e respeitado. Existem duas maneiras de casamento entre o povo Iny, um é o 'hãrabie' e outro 'ixidiròtè. Hãrabie quando a mãe da moça escolhe o rapaz para ser o marido da filha dela. Eles se casavam sem conhecer o noivo ou noiva. O casamento tem lei e regra por isso que o rapaz ou moça não deve de recusar o casamento. Se o rapaz recusar o seu primeiro casamento, ele vai ter que cumprir a punição de casamento.

A punição é simples, mas, é muito complicado para quem recusa o casamento. Só pode casar quando a noiva foi recusada casar com outro. Quando acontece assim, o povo reconhece como o rapaz mal exemplo e sem educação, ele não era mais o exemplo para o seu grupo, não tem confiança, e totalmente não tem moral com as suas comunidades. 
$\mathrm{O}$ ixidiròtè quando o homem ou mulher se disponibilizar para ser o esposo ou esposa. Nesse caso, depende de quem se disponibiliza o aceito ou não. Mas, geralmente é o aceito. Antes que o casamento aconteça a família da moça ou do rapaz, escolhe para ser uma noiva ou para ser um noivo. E, a família combina direitinho para realização de casamento. A família da moça prepara. Este momento é o marcante para o casal, e não deve esquecer o acontecimento.

\section{PINTURA CORPORAL}

Pintura corporal é o fundamental para comunidade indígena identificar como a pessoa a qual o povo que pertence. É por isso que quando nós percebemos a pintura estranha, sabemos que não é do nosso povo, e sim, de outro povo. A pintura corporal é um tipo de ensino.

A pintura corporal tem técnica e não é qualquer um que faz pintura corporal, somente aquele que tem habilidade de fazer a pintura no corpo. A pintura corporal usada nas festas rituais nas cerimônias.

Festa de Aruanã

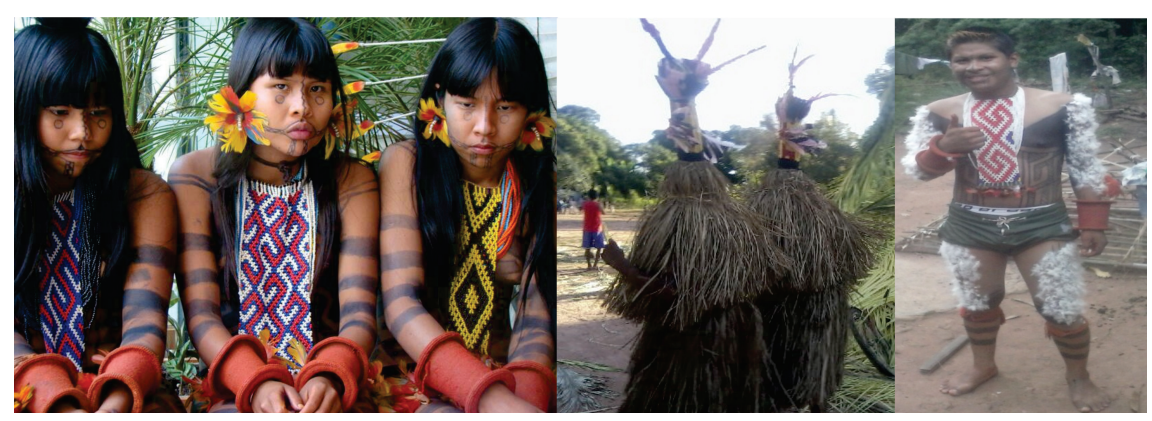

O povo Karajá tem festa de Aruanã. Quando tem festa a moça se pinta corpo inteiro para dançar juntamente com a aruanã.

A pintura corporal tem sua forma. Veja duas pinturas corporais com diferente forma: é da feminina e do masculino. 


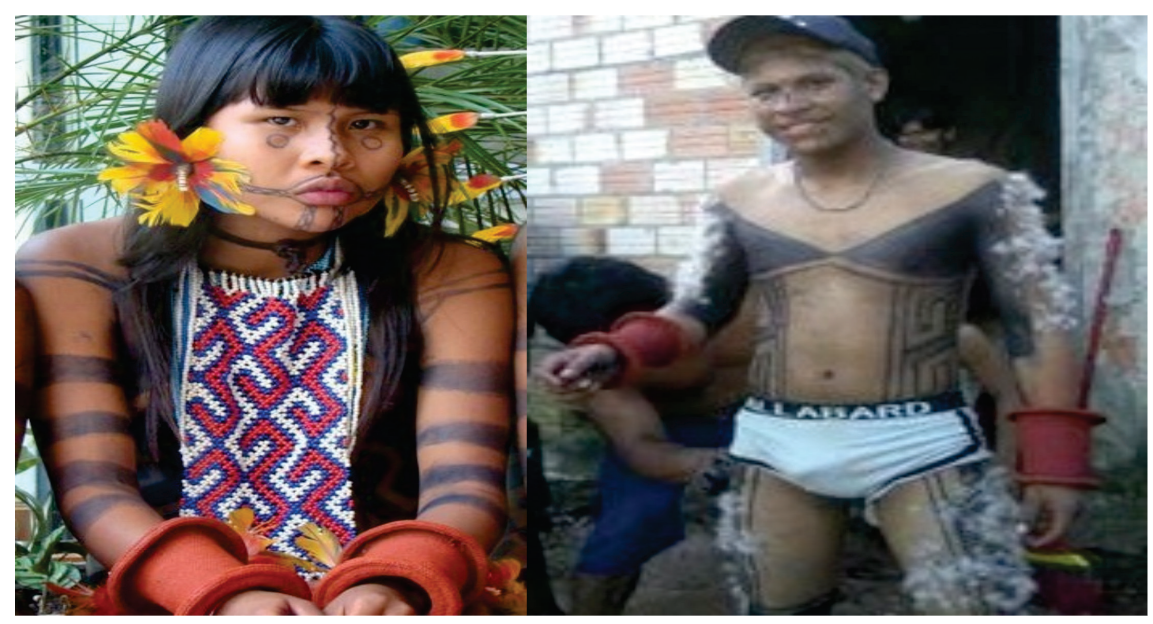

A pintura corporal masculina é diferente do que a feminina. Veja corpo do rapaz está sendo pintado de tinta de jenipapo frente e costa. Observa bem a imagem cada corpo se pinta diferente, o peito, o braço, a barriga, a coxa, o joelho e a perna. Essa forma da pintura corporal especificamente para os homens.

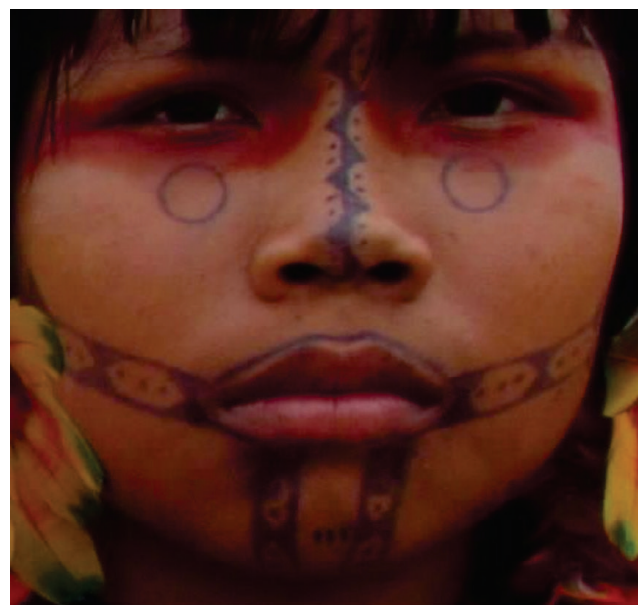

Pintura do rosto 


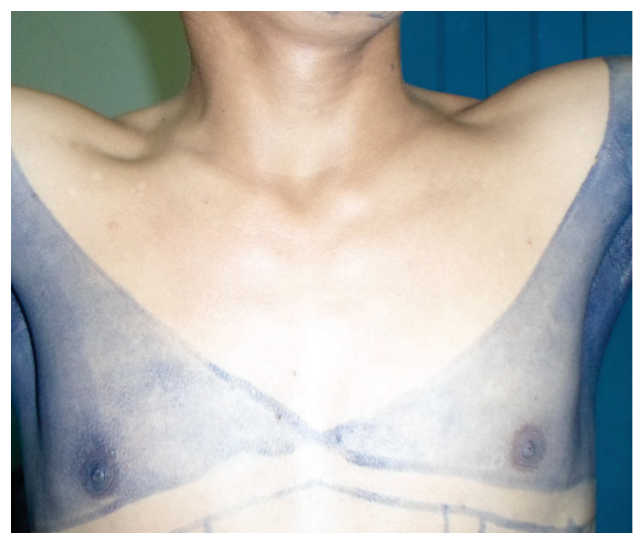

Peito

Frente

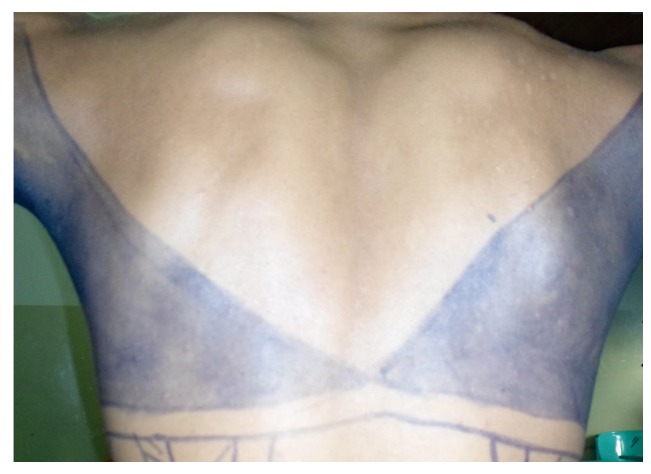

Costa

Chama-se Ixalby

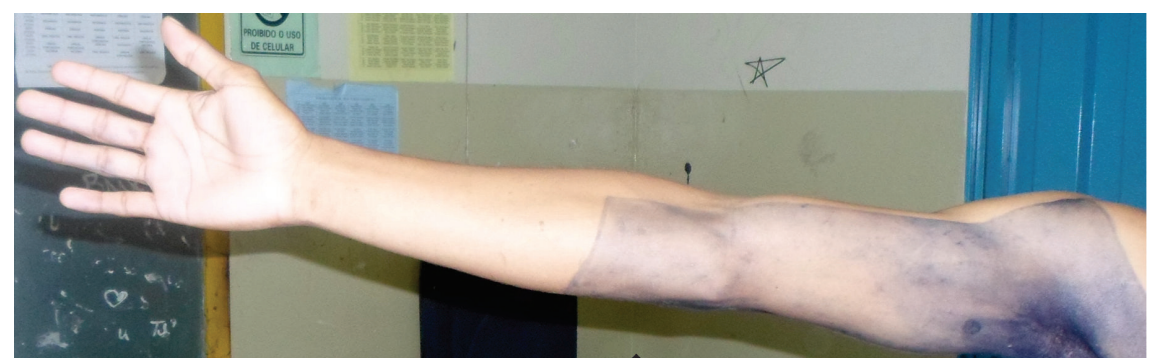

Pintura do Braço

Chama-se derolby 


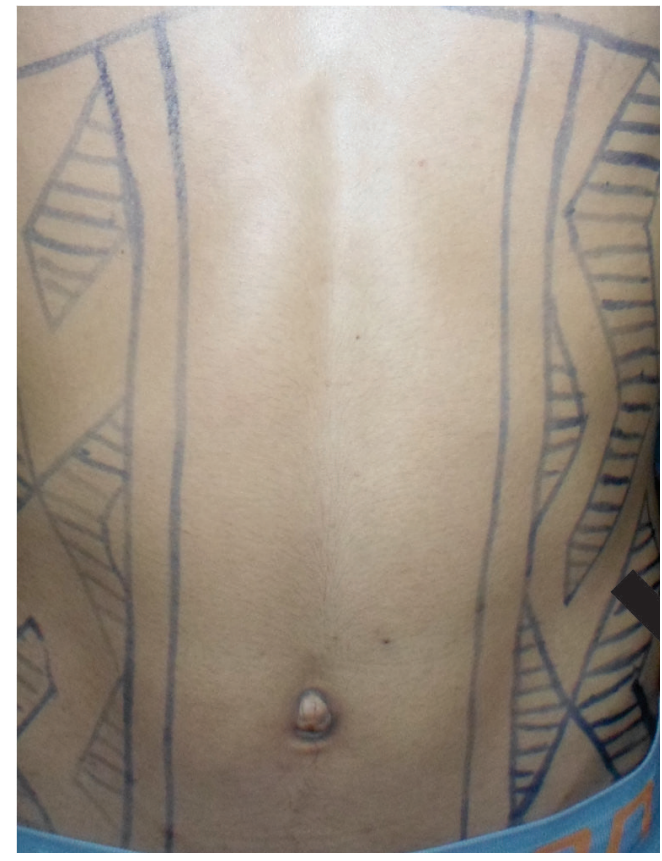

Pintura da barriga chama -se werti

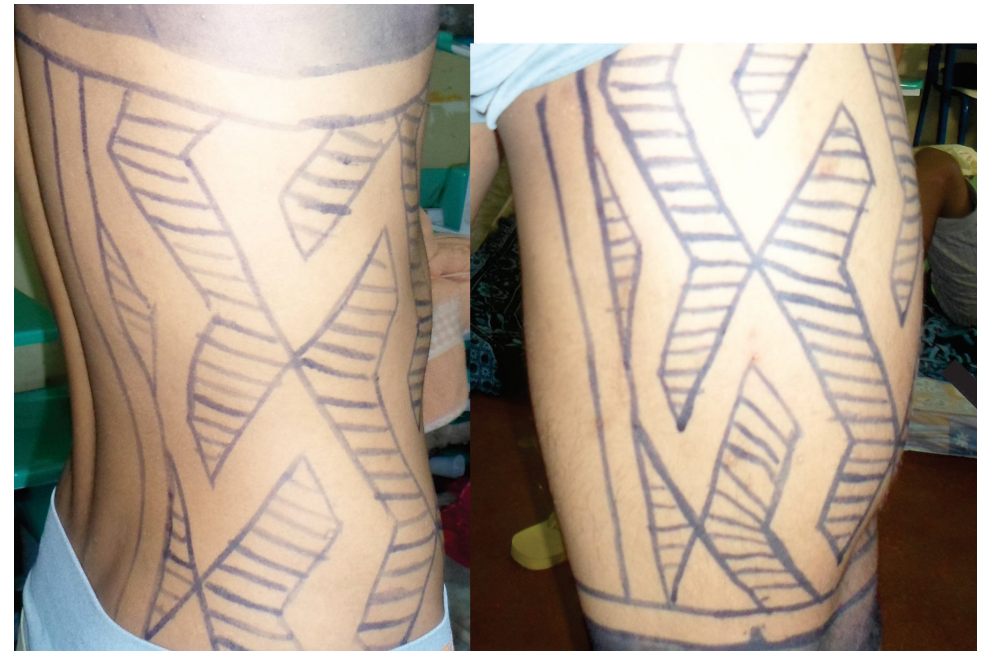

Pintura da coxa chama-se ruti yri 


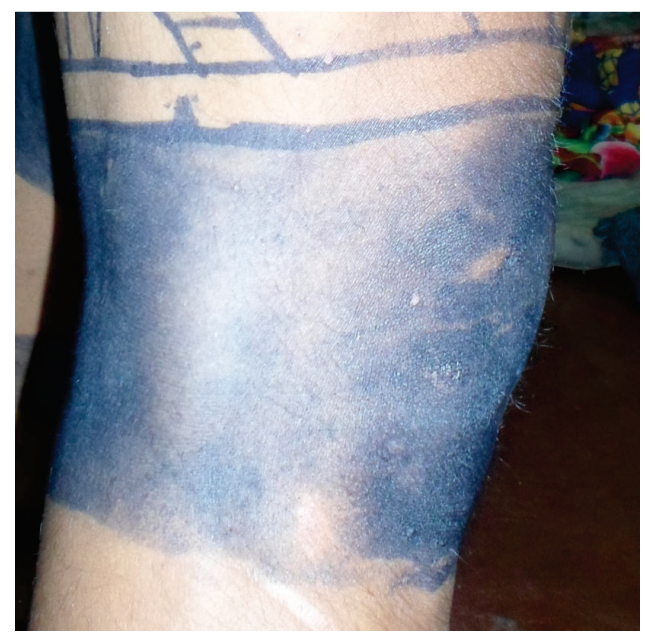

Pintura do joelho chama-se tiohu lby

Pintura da perna chama-se tiyri

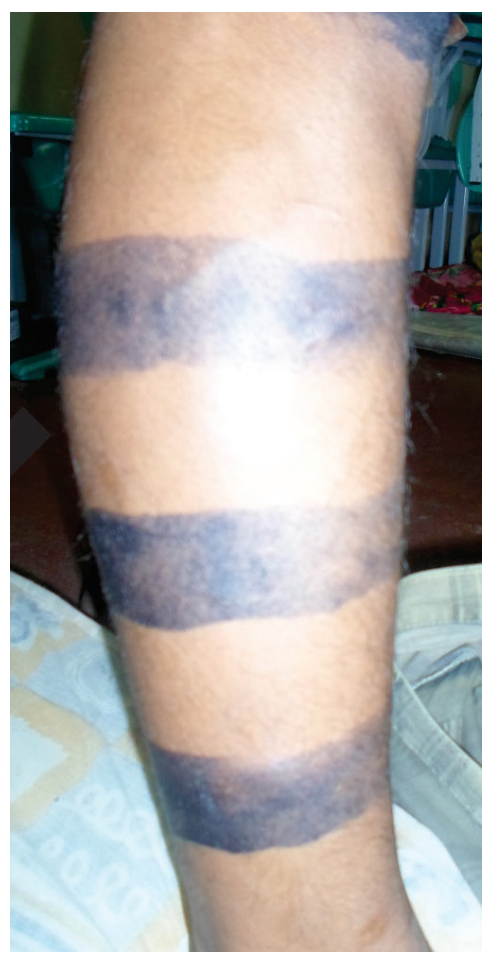

